\title{
Stabilizing Lateritic Soil Using Terrasil Solution
}

\author{
Olumuyiwa S. Aderinola ${ }^{1}$, Emeka S. Nnochiri ${ }^{2}$ \\ ${ }^{1}$ Federal University of Technology, Akure, Nigeria \\ Department of Civil and Environmental Engineering, \\ e-mail: osaderinola@yahoo.com \\ ${ }^{2}$ Afe Babalola University, Ado-Ekiti, Nigeria \\ Department of Civil and Environmental Engineering, \\ e-mail: segunemeka@yahoo.com
}

\begin{abstract}
This study assesses stabilizing lateritic soil using Terrasil solution. Preliminary tests were carried out on six natural soil samples from three borrow pit locations-two soil samples from a particular borrow pit location, for the purpose of identification and classification. Soil samples 1 and 2 from borrow pit 3 were found to be poor, hence, needed stabilization. While the other four samples from borrow pits 1 and 2 were found to be good enough. Engineering property tests such as California Bearing Ratio (CBR), Unconfined Compressive Strength (UCS) and Compaction tests were performed on both the natural soil samples and the stabilized lateritic soil samples which were stabilized by adding terrasil solution in percentages ranging from $0 \%$ to $16 \%$ at $2 \%$ interval. The results showed that the addition of terrasil solution enhanced the strength of the two soil samples from borrow pit 3. For soil sample 1, the unsoaked CBR values increased from $8.4 \%$ at $0 \%$ to optimum value of $30.3 \%$ at $12 \%$ terrasil solution, while for soil sample 2, the unsoaked CBR values increased from $6.2 \%$ to optimum value of $32.0 \%$ at $12 \%$ terrasil solution. It was therefore concluded that the terrasil solution serves as a cheap and effective stabilizing agent for poor soil.
\end{abstract}

Key words: Atterberg limits, geotechnical tests, Lateritic soil, Stabilization, terrasil solution

\section{Introduction}

The origin of expansive soil is related to a complex combination of condition and processes that result in the formation of clay mineral having a particular chemical makeup which, when in contact with water, will expand [1]. All clay soils are not expansive and the degree of expansion varies with the type of clay mineral predominantly present in the soil mass. The presence of montmorillonite in the soils imparts their high swell-shrink potentials [2]. These soils are very hard when dry, but lose strength completely when wet. Pavement structures on poor soil subgrades show early distresses causing the premature failure of the pavement. Stabilization of these types of soils using different additives is a usual practice as it becomes 
uneconomical to replace the foundation material with good quality soils. Many additives such as lime, cement, fly ash, bitumen and different chemicals are being used for stabilization [3].

In most geo- technical projects, it is not possible to obtain a construction site that will meet the design requirements without soil modification. The current practice is to modify the engineering properties of the native problematic soils to meet the design specifications. Nowadays, soils such as, soft clays and organic soils can be improved to meet the civil engineering requirements [4].

Soil stabilization aims at improving soil strength and increasing resistance to softening by water through bonding the soil particles together, water proofing the particles or combination of the two [5]. Usually, the technology provides an alternative structural solution to a practical problem. The simplest stabilization processes are compaction and drainage (if evaporation takes place in wet soil, then the soil becomes stronger). The other process is by improving gradation of particle size and further improvement can be achieved by adding binders to the weak soils [6].

\section{1 Chemical Stabilization}

Under this category, soil stabilization depends mainly on chemical reactions between stabilizer and soil minerals to achieve the desired effect [7]. According to Raymond [8] explained that through soil stabilization, unbound materials can be stabilized with cementitious materials (cement, lime, fly ash, bitumen or combination of these). Chemical stabilization is achieved by mixing appropriate percentages of chemical such as lime, fly ash, bitumen or terrasil. The process of selecting the appropriate chemicals involves the study of the soil type and properties, the design intent for stabilizing the material, the required strength and durability of the product, initial cost/cost savings and environmental consideration [9].

\subsection{Terrasil}

Terrasil are water soluble compound which forms form water clear solution. Terrasil nanotechnology offers a permanent water repellent Nano layer on all types of soils, aggregates and other inorganic road construction materials [10]. The reaction leads to permanent nanosiliconization of the surfaces by converting the water loving silanol groups to water repellent siloxane bonds. The Si-O-Si Siloxane bond is Mother Nature's strongest bond which survives for centuries. The substantial reduction in soil water infiltration and erosion has ultraviolent and thermal stability for over 20 years. The siloxane is non-leachable as it chemically binds to surfaces permanently. Terrasil unique chemical structure makes it water soluble. However, when it applied on the surface and is bonded to the surface, the water repellent characteristic of the molecule dominates on the surface and provide water repellency [11].

Terrasil is defined according to Prakash and Sridharan[12] as an organosilane compound which reacts with soil particles and form hydrophobic (oily) layers on the surface of the soil and clay particles. This make soil particles water insensitive and can be compacted to a better particle interlock state by equipment and traffic forces. Terrasil can treat material ranging from clays to silty sand and gravel. It is a nanotechnology that offers a permanent water repellent nano layer on all types of soils, aggregates and other inorganic road construction materials. The reaction of Terrasil and soil leads to permanent nanosiliconization of the 
surfaces by converting the water loving silanol groups to water repellent siloxane bonds. The siloxane is non-leachable as it chemically binds to surfaces permanently. Terrasil unique chemical structure makes it water soluble. However, when it applied on the surface and is bonded to the substrate, the water repellent characteristic of the molecule dominates on the surface and provide water repellency [13].

Terrasil is an organo-silane technology and forms one of nature's strongest naturally occurring molecular bonds. Furthermore, terrasil covalent bond structure continues to allow treated materials to breathe. The free flow of air through brick and concrete preserves a structure's thermal insulation properties. This unique feature also allows trapped moisture to escape building materials. Water droplets remain too large to penetrate terrasil's hydrophobic barrier, but much smaller water vapor droplets can easily escape. Terrasil prevents mold and mildew; rusting of rebar (reinforcement bar); water damage due to capillary rise; blistering of plaster walls; paint peel-off; efflorescence in cement and brick and fungus growth. It prevents the damaging effects of freezing water's expansion and subsequent cracking; water damage and deterioration of concrete infrastructure; pocking and general damage. By creating a water resistant surface, costly maintenance repairs are minimized and a structures life is prolonged. Terrasil is a nanotechnology soil and infrastructure chemical/agent for road construction, especially in the aspect of soil stabilization, it makes the roads or soil impermeable to water, abrasion and many other benefits. Terrasil mixed with zycobond gives you excellent bonding of road construction materials, erosion control permanently and suppressed dust on the road and your environment. Terrasil is a new concentrate created to make soils, sand, and aggregates repel water. This breakthrough technology makes treated soils $98 \%$ water resistant and delivers proven results in road construction while sharply reducing soil erosion.

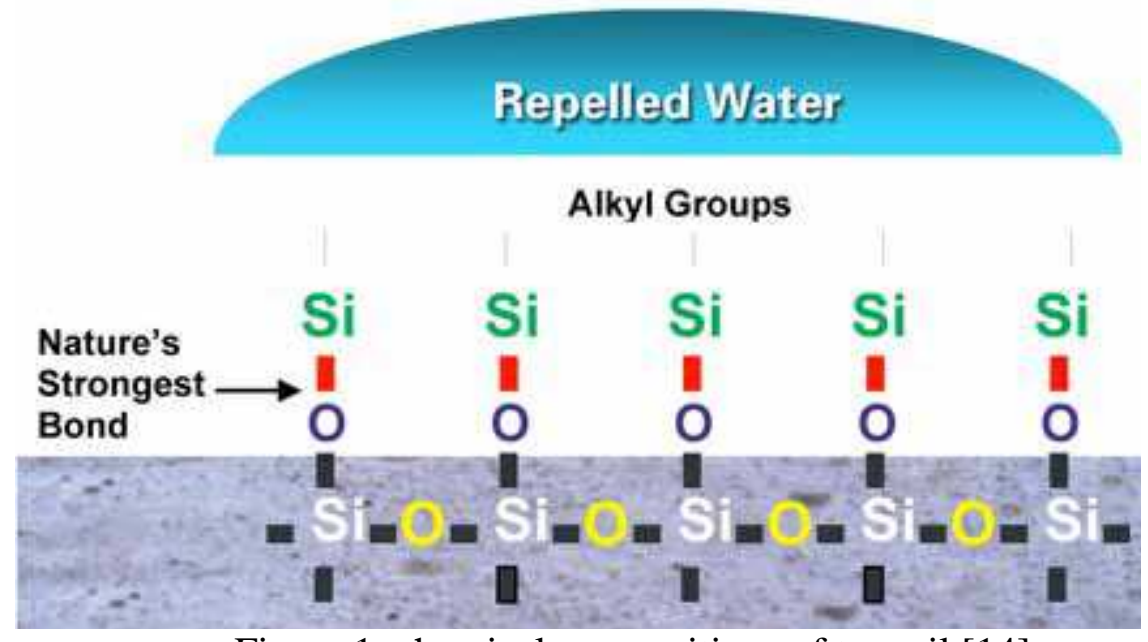

Figure 1: chemical compositions of terrasil [14].

Terrasil mixes easily with water and can be applied using a low-pressure sprayer. Terrasil, zycosoil, and Zycobond are the only water repellents in the world which are applied using water. They require no special equipment and minimal clean-up time. Once applied, Terrasil bonds to become a permanent part of the treated soil or aggregate and provides long-lasting water repellency. While existing polymer technologies are surface coatings that deteriorate 
from UV exposure, Terrasil resists UV degradation and remains stable for years, substantially reducing the expense of continuing repairs. The advantages of the use of terrasil among others include; reduces road surface cracking caused by soils' expansion and contraction, greatly enhances road solidity and longevity where poor quality aggregates are used, increases soils' durability through improved compaction, the patented molecule in Terrasil forms a permanent bond with soils, sands and aggregates to create a barrier against water, saving money on road upkeep and repairs. It is equally useful in the areas of constructing levees and dams, erosion control, hillside stabilization, unpaved paths, excavation stabilization.

\section{Materials and Methods}

The following materials were required for this research: Soil samples, Terrasil and Distill water.

\subsection{Soil Samples}

Six different lateritic samples were sourced from three borrow pits located within Akure and subjected to preliminary tests with at least two samples taken from each borrow pit locations, Assessments of the index properties of the samples-taken from each borrow pit locationsfavors borrow pit 3 samples for stabilization.

\subsection{Terrasil}

Terrasil is a commercially available chemical stabilizer which is used in the present investigation. The Terrasil that was used for this research was bought from VLX group of companies in Lagos and properly kept safe in the Geotechnical Laboratory of Department of Civil Engineering, Federal University of Technology Akure, before use. It is available in concentrated liquid form and is to be mixed with water in specified proportion before mixing with the soil. Technical specifications are shown in Table 1 below:

\begin{tabular}{|l|l|}
\hline Property & Description \\
\hline Appearance & Pale Yellow Liquid \\
\hline Solid Content & $68 \pm 2 \%$ \\
\hline Viscosity at $25^{\circ} \mathrm{C}$ & $20-100 \mathrm{cps}$ \\
\hline Specific gravity & 1.01 \\
\hline Solubility & Forms water clear solution \\
\hline Flash Point & Flammable $12^{\circ} \mathrm{C}$ \\
\hline Terrasil : Water & $1: 200 \mathrm{ml}$ \\
\hline Dosage & $\begin{array}{l}2 \% \text { to } 16 \% \text { at } 2 \% \text { interval by weight of dry } \\
\text { soil }\end{array}$ \\
\hline
\end{tabular}




\subsubsection{Distil water}

The water used throughout the experiment was gotten from a borehole and distilled in the geotechnical engineering laboratory of the Department of Civil and Environmental Engineering, Federal University of Technology Akure, Nigeria.

\subsection{Methods}

Preliminary tests such as Natural Moisture Content Test, specific gravity Test, Grading test, Consistency Limits Test, and compaction Test were performed on the lateritic sample for the determination of index properties of the samples. Constant terrasil - water ratio of 1: 200 was added to the poor lateritic soil (which were samples 1 and 2 from borrow pit number 3) with variations of terrasil solution contents - ranging from $0 \%$ to $16 \%$ at $2 \%$ interval. All proportions of terrasil solution were measured in percentages by weight of the dry soil samples.

Geotechnical tests such as compaction Test and California Bearing Ratio Test - which involve the treatment of poor lateritic soil with terrasil - water solution at a constant ratio of 1:200 were carried out on each of the lateritic soil samples at varying proportions of 2, 4, 6, 8, $10,12,14$ and $16 \%$ of Terrasil solution.

\section{Results and Discussion}

Preliminary tests were carried out for purposes of identification and classification. These tests include: Grain size analysis, Moisture content determination, Specific gravity tests and Atterberg's limit tests.

Table 2: Summary of preliminary results of lateritic soil sample from borrow pit 1

\begin{tabular}{|l|l|l|}
\hline & & \\
Property & Sample 1 & Sample 2 \\
\hline Specific gravity & 2.67 & 2.62 \\
\hline Natural Moisture Content (\%) & 23.9 & 14.4 \\
\hline \% passing through Sieve No 200 & 21 & 31 \\
\hline Liquid Limit (\%) & 31.6 & 39.0 \\
\hline Plastic Limit (\%) & 25.8 & 29.4 \\
\hline Plastic Index (\%) & 5.8 & 9.6 \\
\hline Maximum Dry Density (MDD) (Kg/m $\left.{ }^{3}\right)$ & 2198 & 1864 \\
\hline Optimum Moisture Content (OMC) $(\%)$ & 15.61 & 11.20 \\
\hline AASHTO Classification & A-1-b & A-2-4 \\
\hline
\end{tabular}


Table 3: Summary of preliminary results of lateritic soil sample from borrow pit 2

\begin{tabular}{|l|l|l|}
\hline Property & Sample 1 & Sample 2 \\
\hline Specific gravity & 2.67 & 2.53 \\
\hline Natural Moisture Content (\%) & 18.8 & 18.2 \\
\hline \% passing through Sieve No 200 & 8.5 & 7.9 \\
\hline \% passing through Sieve No 40 & 55 & 59 \\
\hline Liquid Limit (\%) & 31.0 & 35.3 \\
\hline Plastic Limit (\%) & 21.8 & 26.5 \\
\hline Plastic Index (\%) & 9.2 & 8.8 \\
\hline Maximum Dry Density (MDD) $\left(\mathrm{Kg} / \mathrm{m}^{3}\right)$ & 1952 & 2139 \\
\hline Optimum Moisture Content (OMC) $(\%)$ & 10.4 & 13.8 \\
\hline AASHTO Classification & $\mathrm{A}-3$ & $\mathrm{~A}-3$ \\
\hline
\end{tabular}

Table 4: Summary of preliminary results of lateritic soil sample from borrow pit 3

\begin{tabular}{|l|l|l|}
\hline Property & Sample 1 & Sample 2 \\
\hline Specific gravity & 2.69 & 2.64 \\
\hline Natural Moisture Content (\%) & 20.8 & 21.4 \\
\hline \% passing through Sieve No 200 & 47.0 & 53.4 \\
\hline Liquid Limit (\%) & 46.0 & 49.0 \\
\hline Plastic Limit (\%) & 16.3 & 20.3 \\
\hline Plasticity Index (\%) & 29.7 & 28.7 \\
\hline Maximum Dry Density (MDD) $\left(\mathrm{Kg} / \mathrm{m}^{3}\right)$ & 1267 & 1420 \\
\hline Optimum Moisture Content (OMC) (\%) & 19.92 & 22.70 \\
\hline AASHTO Classification & $\mathrm{A}-7-6$ & $\mathrm{~A}-7-6$ \\
\hline Unsoaked CBR (\%) & 8.4 & 6.2 \\
\hline
\end{tabular}

Table 5: Compaction tests results for borrow pit 3, Sample 1

\begin{tabular}{|l|l|l|l|}
\hline Percentage of Laterite $(\%)$ & $\begin{array}{l}\text { Percentage of Terrasil } \\
\text { Solution }(\%)\end{array}$ & MDD $\left(\mathrm{Kg} / \mathrm{m}^{3}\right)$ & OMC (\%) \\
\hline 100 & 0 & 1267 & 19.92 \\
\hline 98 & 2 & 1590 & 19.05 \\
\hline 96 & 4 & 1668 & 17.50 \\
\hline 94 & 6 & 1697 & 17.20 \\
\hline 92 & 8 & 1707 & 17.00 \\
\hline 90 & 10 & 1769 & 16.43 \\
\hline 88 & 12 & 1785 & 15.97 \\
\hline 86 & 14 & 1717 & 18.95 \\
\hline 84 & 16 & 1608 & 19.24 \\
\hline
\end{tabular}


Table 6: Compaction tests results for borrow pit 3, Sample 2

\begin{tabular}{|l|l|l|l|}
\hline Percentage of Laterite (\%) & $\begin{array}{l}\text { Percentage of Terrasil } \\
\text { Solution }(\%)\end{array}$ & MDD $\left(\mathrm{Kg} / \mathrm{m}^{3}\right)$ & OMC (\%) \\
\hline 100 & 0 & 1420 & 22.70 \\
\hline 98 & 2 & 1559 & 20.22 \\
\hline 96 & 4 & 1608 & 19.84 \\
\hline 94 & 6 & 1678 & 19.06 \\
\hline 92 & 8 & 1760 & 18.41 \\
\hline 90 & 10 & 1793 & 18.10 \\
\hline 88 & 12 & 1942 & 17.92 \\
\hline 86 & 14 & 1766 & 19.35 \\
\hline 84 & 16 & 1633 & 20.90 \\
\hline
\end{tabular}

Table 7: CBR tests results for borrow pit 3, Sample 1

\begin{tabular}{|l|l|l|}
\hline Percentage of Laterite $(\%)$ & Percentage of Terrasil Solution (\%) & Unsoaked CBR (\%) \\
\hline 100 & 0 & 8.4 \\
\hline 98 & 2 & 11.1 \\
\hline 96 & 4 & 14.4 \\
\hline 94 & 6 & 16.3 \\
\hline 92 & 8 & 20.3 \\
\hline 90 & 10 & 25.4 \\
\hline 88 & 12 & 30.3 \\
\hline 86 & 14 & 26.1 \\
\hline 84 & 16 & 24.8 \\
\hline
\end{tabular}

Table 8: CBR tests results for borrow pit 3, Sample 2

\begin{tabular}{|l|l|l|}
\hline Percentage of Laterite $(\%)$ & Percentage of Terrasil Solution (\%) & Unsoaked CBR (\%) \\
\hline 100 & 0 & 6.2 \\
\hline 98 & 2 & 13.5 \\
\hline 96 & 4 & 17.3 \\
\hline 94 & 6 & 18.7 \\
\hline 92 & 8 & 21.7 \\
\hline 90 & 10 & 26.3 \\
\hline 88 & 12 & 32.0 \\
\hline 86 & 14 & 27.9 \\
\hline 84 & 16 & 25.5 \\
\hline
\end{tabular}

Tables 2 and 3 show that the soil samples from borrow pits 1 and 2 were good enough and therefore needed no stabilization, while soil samples 1 and 2 from borrow pit 3 are poor in strength, thus, necessitating the need for stabilization. Tables 5 and 6 show the relationship between the Maximum Dry Density (MDD) and Optimum Moisture Content (OMC) with variations of water - terrasil ratio contents. The result indicated that between $0 \%$ and $12 \%$ 
terrasil solution, the MDD values for both samples generally increased and the OMC generally reduced. For soil sample 1, the MDD increased from $1267 \mathrm{Kg} / \mathrm{m}^{3}$ at $0 \%$ to 1785 $\mathrm{Kg} / \mathrm{m}^{3}$ at $12 \%$, for sample 2, MDD increased from $1420 \mathrm{Kg} / \mathrm{m}^{3}$ at $0 \%$ to $1942 \mathrm{Kg} / \mathrm{m}^{3}$ at $12 \%$. With the addition of more terrasil solution, that is, at $14 \%$ and $16 \%$, values of MDD in both samples reduced and OMC values increased. Increased MDD may be due to a decrease in the surface area of lateritic soil sample arising from the reaction of terrasil as an organo - silicon compound which react with soil particles on a molecular level and makes each and every particles waterproofed [16]. According to [17], an increase in MDD is a good indication of improvement in soil property, whereas a reduction in $\mathrm{OMC}$ enhances the workability of a good soil. Also the result shows that the OMC values decreased with increase in the terrasil water ratio before the optimum point- which implies the reaction of terrasil molecules with water generates silinol groups. These silinol groups condense with silinol groups of the soil particles and forms Si-O-Si bonds. This chemical reaction between terrasil and soil particles imparts hydrophobic groups on the surface. This hydrophobic group will not allow soil particles to wet with water. At the optimum moisture, there was a structural adjustment which induced the peak strength with corresponding optimum moisture content for the sample which was usually the lowest optimum moisture content for the stabilized soil. While the reduction in MDD values as a result of further addition of terrasil solution - may be due to excess organo-silanes that could not be mobilized for the reaction which consequently make the solution to be less reactive and therefore forming weak bonds. Increase in OMC may be due to the addition of terrasil solution which decreases the the quantity of free silt and clay fraction and coarser materials with larger surface areas are formed [18]. Tables 7 and 8 show that for the increasing addition of terrasil solution, CBR value rose from $8.4 \%$ at $0 \%$ to optimum value of $30.3 \%$ at $12 \%$ terrasil solution, for sample 1 . For sample 2, the CBR rose from $6.2 \%$ at $0 \%$ terrasil solution to $32.0 \%$ at $12 \%$ terrasil solution before reducing in values to $27.9 \%$ and $25.5 \%$ at $14 \%$ and $16 \%$ terrasil solution respectively.

\section{Conclusions}

The procedures for the various tests were carried out in accordance with that stipulated in BS 1377-1990: 1-8 [19] and British Standards (BS) 1924 [20].Using terrasil reduced the plasticity indices of the soil therefore improving the strength property of the soil. CBR values increased with the increase in percentage of terrasil solution. Terrasil serve as a cheap stabilizing agent for poor soil.

\section{References}

[1] Chen, F. H. (1988). Foundation on Expansive Soils. Elsevier Publications Co. Amsterdam.

[2] Zineb, B., Sidi, M. A. M., Abdelmalek, B. (2013). Laboratory Study on the Influence of Mineral Salts on Swelling $\left(\mathrm{Kcl}, \mathrm{Mgcl}_{2}\right)$. Earth Science Research, Vol. 2, No 2. Published by Canadian Science and Education.

[3] Sharma, N. K. Swain, S.K., Sahoo, U.C. (2012). Stabilization of a Clayey Soil with Fly Ash and Lime: A Micro Level Investigation. Geotechnical and Geological Engineering, Oct. 2012, Vol. 30, Issue 5, Pp.1197-1205. 
[4] Road Research Laboratory. (1968). The Protection of Subgrades and granular Subbases and Bases. London: H.M.S.O.

[5] Little, D.N. and Nair, S. (2009). Recommended Practice for Stabilization of Subgrade Soils and Base Materials. $3^{\text {rd }}$ Edition. Texas Transportation Institute, Texas A\&M University College Station, Texas. 2009.

[6] Lekla B.M., Goutham S. and Ravi Shankar A.V. (2013). Laboratory Investigation of Soil Stabilized with Nano Chemical. Proceedings of Indian Geotechnical Conference. India December 22-24, 2013.India: Rookee, 18-25.

[7] Wright-Fox, R., Macfarlane, J.G. and Bibbens, R.F. (1993). Alternate Chemical Soil Stabilizer: Minor Research Report. $3^{\text {rd }}$ Edition. London: CalTrans publisher.

[8] Raymond S. (1961). Pulverised Fuel Ash as an Embankment Material. London: Institute of Civil Engineers.

[9] Merritt, F.S. Loftin M.K. and Rickett J.T. (1995) Civil Engineering handbook. Florida: University Press Of Florida.

[10] www.zydexindustries.com. Zydex Industries. (2015) (accessed 1/03/2015)

[11] Sherwood, P. T. (1993). Soil Stabilization with Cement and Lime. State of the Art Review. London: Transport Research Laboratory, HMSO

[12] Prakash, K., Sridharan. (2004) A. Free Swell Ratio and Clay Mineralogy of Fine grained Soils. Geotech. Test. J. Vol. 27(2), 220-225

[13] www.zydexindustries.com. Zydex Industries. (2015) (accessed 1/03/2015)

[14] www.zydexindustries.com. Zydex Industries. (2015) (accessed 1/03/2015)

[15] www.zydexindustries.com. Zydex Industries. (accessed 1/03/2015)

[16] Joel, M. and Edeh, J.E. (2015). Comparative Analysis of Cement and Lime Modification of Ikpayongo Laterites for Effective and Economic Stabilization. Journal of Emerging Trends in Engineering and Applied Sciences (JETEAS) 6 (1): 49-56.

[17] Amu, O.O., Owokade, O. S., Shitan, O.I. (2011). Potentials of Coconut Shell and Husk Ash on the Geotechnical Properties of Lateritic Soil for Road Works. International Journal of Engineering and Technology, Vol. 3 (2), (2011), 87-94.

[18] Fattah, M.Y., Rahil, F.H., Al-Soudany, K. Y. H. (2013). Improvement of Clayey Soil Characteristics Using Rice Husk Ash. Journal of Civil Engineering and Urbanism, 3(1): 12-18.

[19] British Standard Institution. (1990). Methods of Test for Soils for Civil Engineering Properties (1377). British Standard Institution: London.UK.143.

[20] British Standards( BS) 1924. (1990). Methods of Test for Stabilized Soils. British Standards Institutions: London, UK. 
